\title{
On the precise measurement capability of the direct microscopic measurement method for wear volume characterization
}

\author{
Enbiya Türedi $^{1}$ \\ ${ }^{1}$ Kocaeli University, Faculty of Engineering, Dept. of Metallurgical and Materials Eng. 41380 \\ Kocaeli, Turkey
}

\begin{abstract}
There are plenty of methods for determining the wear volume after a wear test. Due to the geometrical assumptions, some of them could unfortunately lead to mistaken results. It has been shown that a novel method, the direct microscopic measurement, is able to calculate the wear volume on a specimen surface very precisely and accurately [1-2]. It is based on creating a series of line profiles perpendicular to the wear scar. This novel method, however, needs to be characterized in terms of measurement limitations and minimum detectable volume capability. For example, how small or how shallow a wear scar could be calculated or measured with this method, must be determined. For this purpose, it has been prepared a series of wear test specimens exposed to the different amounts of wear in a "pin-on-disk" type test rig. As specimens, two different non-ferrous mold materials, Al bronze alloys, were selected and prepared metallographically. Counterpart materials were inox steel and bearing steel balls with diameter of $6 \mathrm{~mm}$. Normal load was set to $5 \mathrm{~N}$. Test configurations were set to $1,5,10$ and $100 \mathrm{~m}$ of sliding distance values, in turn. Wear tests were conducted in according to ASTM G99 standard. Wear volume results were determined both direct microscopic measurement and also a 3D optical microscope methods. Comparison results showed that the novel method could be successfully used for wear volume calculations even with small amounts of wear volume conditions.
\end{abstract}

\section{Introduction}

Various methods [1-5] and approaches [6-8] for determining worn volume at specimen surfaces after wear tests have been presented in literature. The results in some methods measuring wear volume based on a series of geometrical assumptions may show up with high error margin [9]. ASTM G99 Standard [10] defines a wear test performed in a "pinon-disk" or "ball-on-disk" type tribometer. The standard predicates the wear volume on determining worn amount in specimen surfaces, and requires that as a priority this volume amount should be measured by means of profilometry. On the other hand it implies that volume loss can also be determined using weight loss. The last but not least it provides math formulae for volume loss calculations, if only one of the pairs has solely worn [10]. Sharma et al. [7] however presented new updated math formulae allowing volume loss 
calculations in the case of both friction test pairs have already worn. Nevertheless, it has been shown [9] that this calculation method may lead to results with high error margin, too.

According to a novel method [8,9], volume loss in worn surfaces can be precisely determined using a reflective type light microscope. This novel method is based on creating a series of line profiles through wear scar. Limited depth of field feature of reflective type light microscopes at relatively high magnification levels is utilized at the formation of these line profiles. In former studies [8,9], it has been shown that the successful measurements in wear scars of 5-60 $\mu \mathrm{m}$ in-depth levels can be done. Now this time, in the present study it is investigated that whether much narrower and shallower wear scars with this novel method may successfully be measured or not.

\section{Experimental}

First of all, dry friction tests were performed using "ball-on-disk" type tribometer. Two different $\mathrm{Al}$ bronze (sort of $\mathrm{Cu}-\mathrm{Al}$ alloy) specimens in dimensions of $30 \times 30 \times 10 \mathrm{~mm}$ were metallographically polished and prepared for dry friction tests. Polished surfaces were marked to be divided into four equal parts that every polished surface part was reserved for one friction test run. Hardness values of the flat specimens and counterpart balls used in dry friction tests were listed in Table 1. Tribological test conditions were presented in Table 2. Additionally, friction tests were performed without lubrication at room temperature. The main parameter in friction test was total friction distance. It is aimed to obtain various volume loss amounts at friction pairs' surfaces.

Table 1. Main properties of the dry friction test pairs

\begin{tabular}{|c|c|c|c|c|}
\hline Specimen & $\begin{array}{c}\text { Hardness } \\
\text { (HV-10) }\end{array}$ & $\begin{array}{c}\text { Counterpart } \\
\text { (Ball) Material }\end{array}$ & $\begin{array}{c}\text { Hardness } \\
\text { (HV-10) }\end{array}$ & $\begin{array}{c}\text { Diameter } \\
\text { (mm) }\end{array}$ \\
\hline Al bronze 1 & 204.8 & AISI 316 & 334.5 & 6.0 \\
\hline Al bronze 2 & 180.4 & AISI 52100 & 793.1 & 6.0 \\
\hline
\end{tabular}

Table 2. Dry friction test conditions

\begin{tabular}{|l|c|c|c|}
\hline Test & Load (N) & Sliding Speed (m/s) & Total Distance (m) \\
\hline 1 & & & 1 \\
\cline { 1 - 1 } 2 & 5.0 & 0.08 & 5 \\
\hline 3 & & & 10 \\
\cline { 1 - 1 } & & & 100 \\
\hline
\end{tabular}

After dry friction tests the worn surface investigations were performed using a reflective type light microscope (Olympus BX41M LED) as well as a 3D Optical Microscope (Bruker Contour GT-K0) for determining worn volume loss and comparing the results. Four line profiles from every wear scar were derived using novel method $[8,9]$ in the reflective type light microscope mentioned above. The measurement points' coordinates (in horizontal and vertical directions) which build the line profiles, were transferred into MS Excel spreadsheets and then polynomial functions best fitted on line profiles were calculated by curve fitting feature of MS Excel. The cross-sectional area between curves of surface 
profiles before and after wear test was calculated by solving a series of definite integrals with the help of GNU Octave [11] software. Since the wear scars are in circular form, total volume loss amounts at surfaces were calculated from the cross-sectional area values multiplying with perimeter values. In order to reveal the effectiveness of the novel method and its applicability to various wear scars with different depth profiles, the results of different volume loss measurement methods were compared assuming that the $3 \mathrm{D}$ optical microscope yielding most accurate and reliable results. Additionally, another calculation method proposed by Sharma et al. [7] as well as the calculated weight loss levels from volume amounts were listed for comparison purposes.

\section{Results and Discussion}

The selected 3D surface contour profiles from specimens were presented in Fig. 1 and 2. Relatively smallest voluminous surface contour profiles among others are shown in Fig. 1, while relatively most voluminous ones given in Fig. 2 . The line profiles obtained with the novel method on the very same wear scars are shown in Fig. 3.
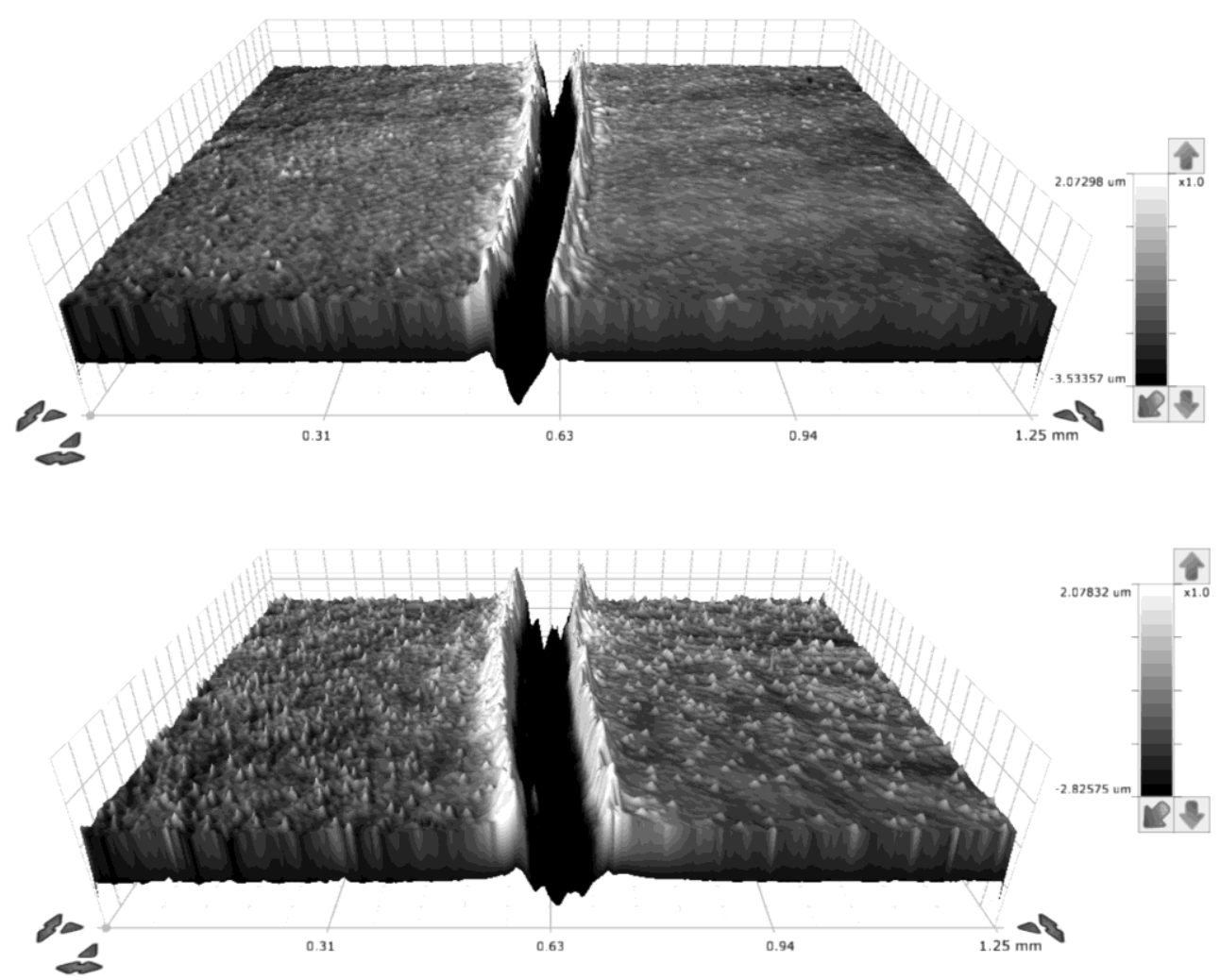

Fig. 1. 3D surface profiles of the specimen 1 and 2 after Test 1 conditions, respectively. These are relatively smallest wear scars. It must be noted that vertical dimension exaggerated. 

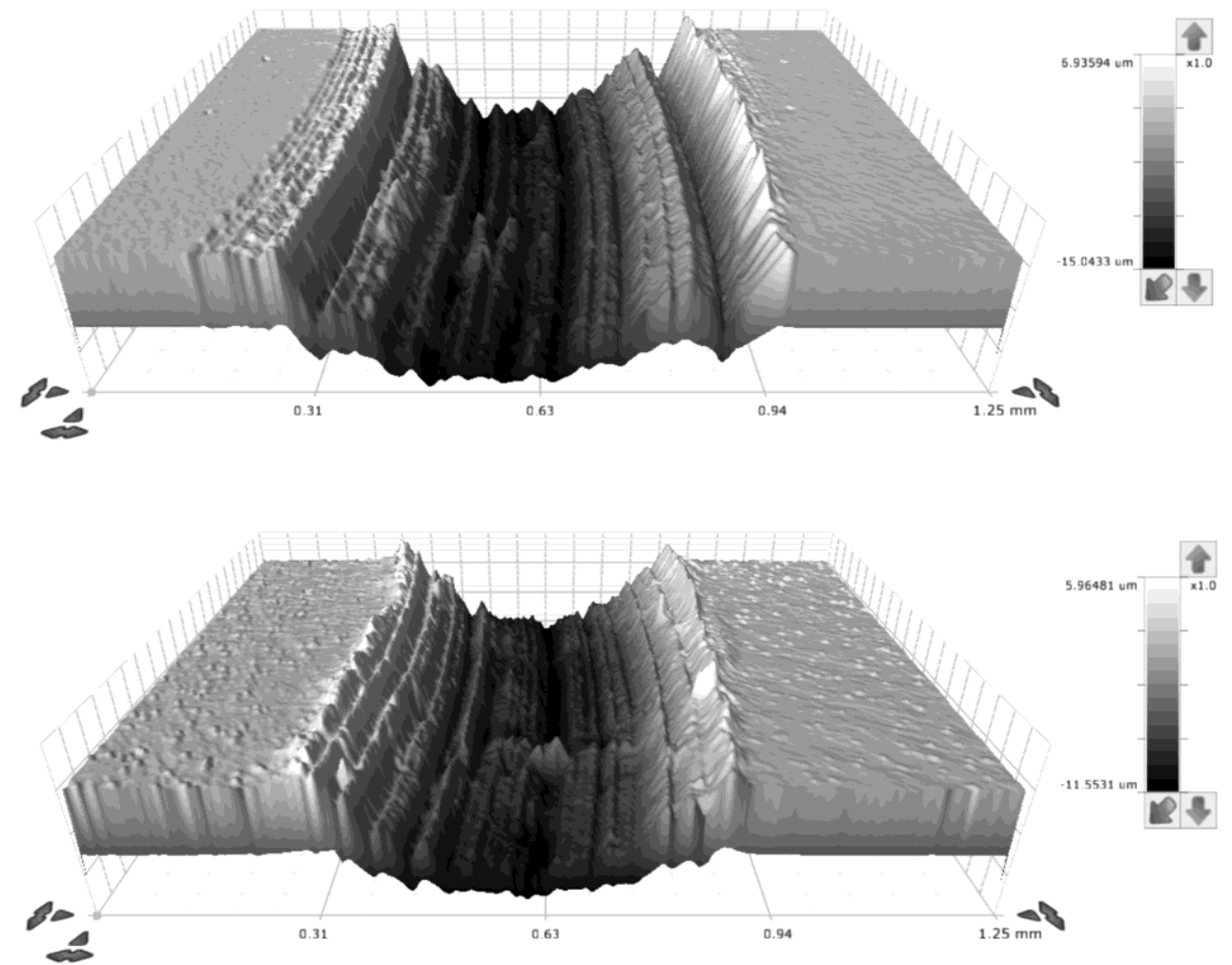

Fig. 2. 3D surface profiles of the specimen 1 and 2 after Test 4 conditions, respectively. These are relatively biggest wear scars. It must be noted that vertical dimension exaggerated.

The detailed wear scar images revealed the pile-up formation [12] at both sides of the scar, parallel to friction direction. It implies that there has been micro-ploughing [13] during friction test. Moreover, it denotes the flat specimens suffering plastic deformation, more or less. Due to the repetitive progress of the ball on the wear scar, abrasive wear mechanism also occurred besides plastic deformation.

It should be emphasized that the novel method does not enable acquiring a sort of threedimensional surface profile but a simple line profile, instead. In the case of the wear, scar profile has a wavy structure due to abrasive wear tracks as seen in Fig. 1 and 2, the proposed novel method successfully reflects this kind of topographic details in the line profiles (see Fig. 3b and c). Therefore the error margin in the calculation of the crosssectional area in the wear scar decreases significantly and hence the total volume loss due to wear in the specimen can be accurately measured. However, this wavy structure in the wear scar cannot be taken into account in other calculation methods proposed in ASTM Standard [10] and Sharma et al. study [7] because those approaches assume wear scar profile is as smooth as the ball (counterpart) radius. This geometrical assumption increases the error margin in these methods, even though the worn amount in the ball tip is taken into consideration. 

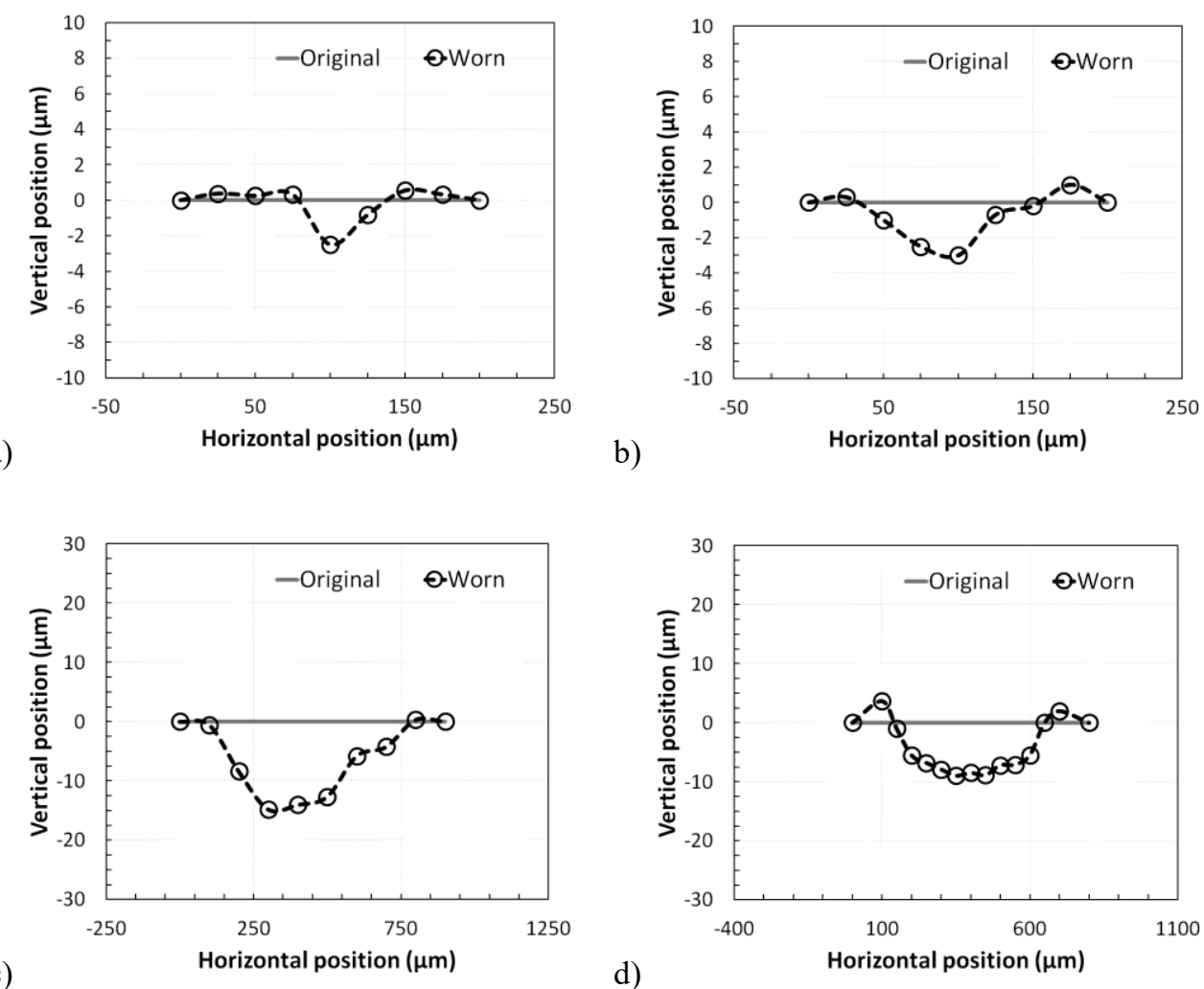

Fig. 3. The obtained line profiles of the selected wear scars using novel method: a) Test 1 conditions on specimen 1, b) Test 1 on Specimen 2, c) Test 4 on Specimen 1 and d) Test 4 on Specimen 2.

A general comparison table for the worn volume amounts in specimens is given in Table 3. Average values of volume loss, as well as their standard deviation results obtained from specimens using three different methods, were listed. Lastly, weight loss equivalent values were added for every test conditions. These equivalent values were calculated from 3D Optical Microscope volume loss results using alloys' density values. The results were written based on precision balance measurement sensitivity $(0.1 \mathrm{mg})$. Consequently, some weight loss values were very small and it is not possible to be weighed correctly on a precision balance.

According to the results in Table 3, worn volume loss values obtained with the novel method seem to be very close to those of obtained with 3D Optical Microscope method or at least their standard deviation intervals are always in the same margin. In order to see this clearly, the comparison diagrams were also drawn for both flat specimens in Fig. 4 and 5, respectively. As can be seen, the very close and reasonable results from both short and long test runs were obtained between the novel and 3D Optical Microscope methods. However, the results obtained according to the calculation procedure proposed by Sharma et al. study [7], were not able to succeed to reflect the correct values comparatively. For instance, it has been found that the average volume loss values and sometimes standard deviation intervals have fallen apart from those of 3D Optical Microscope method on both specimen 1 and 2, except Test 2 conditions. 
Table 3. Comparison table of volume loss amounts obtained from various methods.

\begin{tabular}{|c|c|c|c|c|c|c|c|c|}
\hline \multirow{3}{*}{ Specimen } & \multirow{3}{*}{ Test } & \multicolumn{2}{|c|}{ Novel Method } & \multicolumn{2}{|c|}{ 3D Opt. Micr. } & \multicolumn{2}{|c|}{ Ref. 7} & \multirow{3}{*}{$\begin{array}{c}\text { Weight } \\
\text { Loss } \\
\text { Equiva- } \\
\text { lent } \\
\text { (mg) }\end{array}$} \\
\hline & & Volume & St. Dev. & Volume & St. Dev. & Volume & St. Dev. & \\
\hline & & \multicolumn{2}{|c|}{$\left(\times 10^{-3} \mathrm{~mm}^{3}\right)$} & \multicolumn{2}{|c|}{$\left(\times 10^{-3} \mathrm{~mm}^{3}\right)$} & \multicolumn{2}{|c|}{$\left(\times 10^{-3} \mathrm{~mm}^{3}\right)$} & \\
\hline \multirow{4}{*}{$\begin{array}{c}\text { Specimen } \\
1\end{array}$} & 1 & 2.89 & 0.27 & 2.22 & 0.41 & 0.20 & 0.05 & 0.0 \\
\hline & 2 & 10.05 & 1.38 & 12.87 & 2.44 & 10.63 & 1.96 & 0.1 \\
\hline & 3 & 17.20 & 3.12 & 20.10 & 2.54 & 33.64 & 4.85 & 0.1 \\
\hline & 4 & 184.14 & 7.80 & 183.73 & 9.77 & 219.67 & 24.84 & 1.4 \\
\hline \multirow{4}{*}{$\begin{array}{c}\text { Specimen } \\
2\end{array}$} & 1 & 4.21 & 1.01 & 5.14 & 1.38 & 0.94 & 0.19 & 0.0 \\
\hline & 2 & 7.65 & 2.59 & 7.41 & 0.60 & 4.76 & 2.94 & 0.1 \\
\hline & 3 & 13.03 & 1.70 & 11.95 & 1.42 & 17.77 & 3.79 & 0.1 \\
\hline & 4 & 91.97 & 4.80 & 98.26 & 9.44 & 115.06 & 10.58 & 0.7 \\
\hline
\end{tabular}

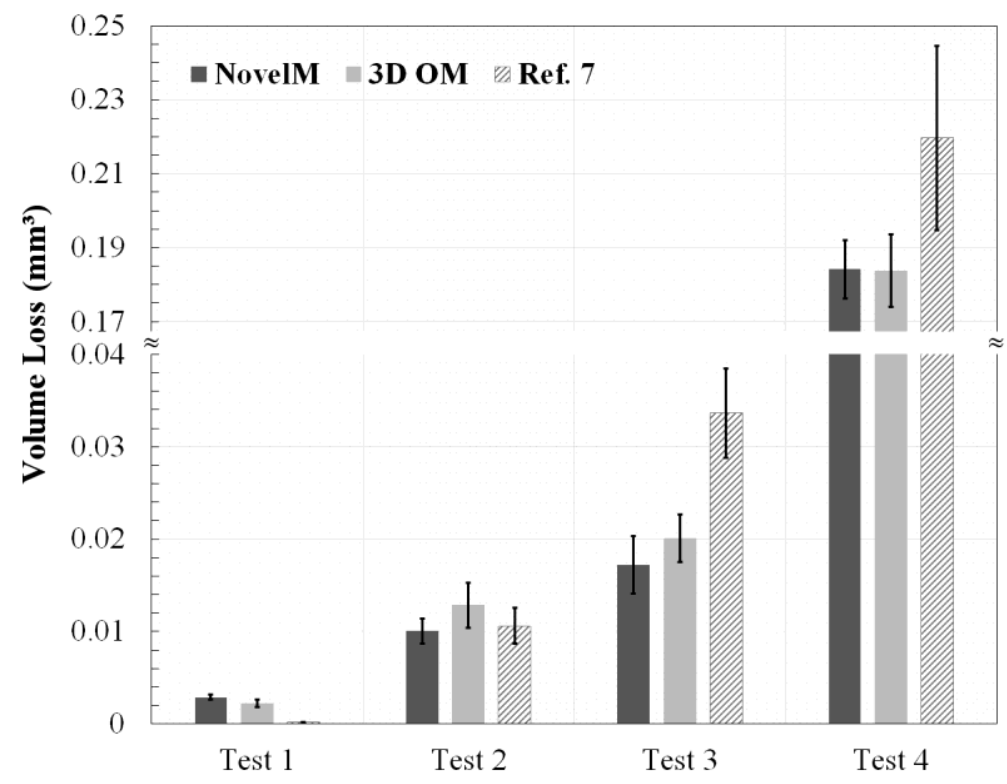

Fig. 4. Comparison diagram for volume loss values of Specimen 1, obtained from various methods (NovelM: Novel method, 3D OM: 3D Optical Microscope, Ref. 7: Calculation in [?]). 


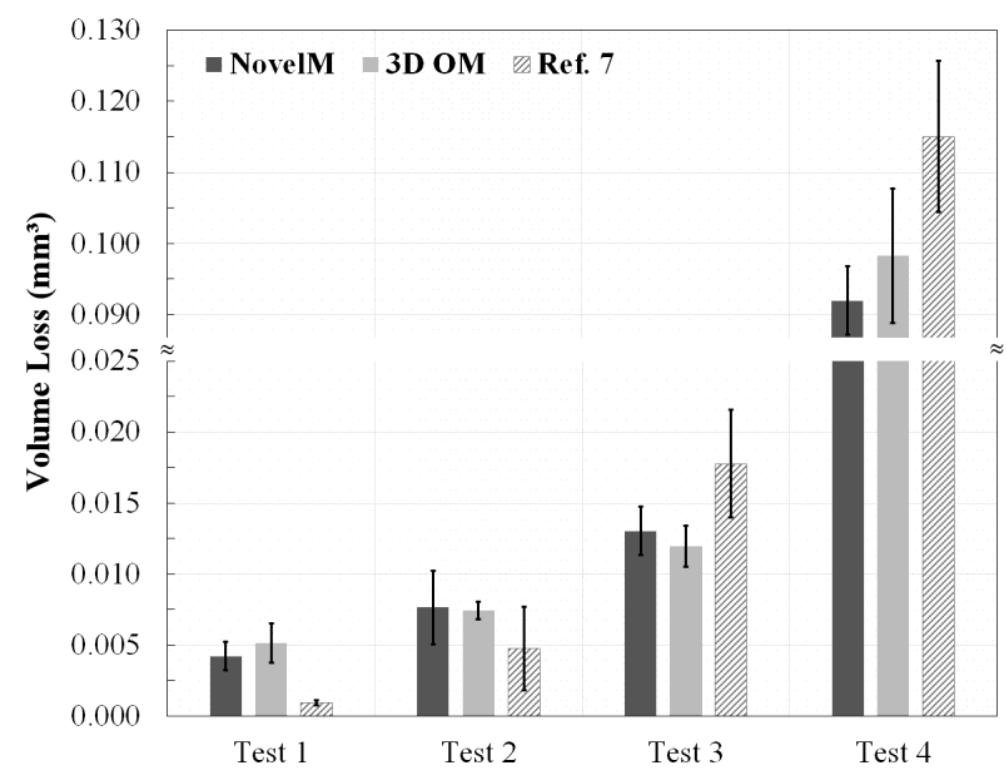

Fig. 5. Comparison diagram for volume loss values of Specimen 2, obtained from various methods.

\section{Conclusions}

A novel method for wear volume determination was introduced in previous studies $[8,9]$. This novel method includes the investigation of the worn surface using a reflective type light microscope. The profilometric changes through a cross-section of a wear scar can be detected precisely using limited depth of field feature of the light microscope at high magnifications. The measurement points and their gathered positional data on both vertical and horizontal directions can be recorded in an Excel Spreadsheet to build XY scatter diagram, and the curve-fitting functions including polynomial equations on measurement point coordinates can be conducted. The area between surface profile lines before and after the wear test yields the cross-sectional area of the wear scar, which can be converted into total worn volume loss using perimeter or length data depending upon wear scar shape.

In order to compare and evaluate the methods, four different wear test conditions were performed on two different friction pairs. 3D Optical Microscopy method was assumed to yield most accurate and reliable values in terms of volume loss determination. The proposed novel method yielded quite close and reasonable volume loss values to those of 3D Optical Microscopy technique. Additionally, the average volume loss values obtained from the novel method fall into standard deviation interval of the 3D Optical Microscopy method in all cases.

Another calculation method proposed by Sharma et al. [7] yielded average results with a relatively higher error margin, mainly due to its geometrical assumptions. Its average values were quite lower than those of reference values were in Test 1 and 2, but also highly over than those of reference ones were in Test 3 and 4.

It has also been shown that weight loss method was not suitable to evaluate and measure the volume loss using density values. Because weight loss values were considerably small in quantity in most cases to be able to weigh in a laboratory type analytical balance with its typical measurement precision of $0.1 \mathrm{mg}$. 
The technical support and contribution of Mr. Onur Birbaşar from Assan Aluminum, Dilovasi Facility (in Turkey) by using the 3D Optical Microscope is gratefully acknowledged.

\section{References}

1. E. P. Whitenton and P. J. Blau, Wear 124, 291 (1988).

2. I. Sherrington and E. H. Smith, Wear 125, 271 (1988).

3. I. Sherrington and E. H. Smith, Wear 125, 289 (1988).

4. J. Qu and J. J. Truhan, Wear 261, 848 (2006).

5. C. Chattopadhyay, S. Sangal, K. Mondal, and A. Garg, Wear 289, 168 (2012).

6. M. Kalin and J. Vižintin, Wear 237, 39 (2000).

7. S. Sharma, S. Sangal, and K. Mondal, Wear 300, 82 (2013).

8. E. Türedi, in 1st Int. Mediterr. Sci. Eng. Congr. (IMSEC 2016) (Adana-Turkey, 2016), pp. 2602-2610.

9. E. Türedi, Utilization of the Limited Depth of Field Feature in Light Microscopy for Determining Wear Volume (2018).

10. Astm, ASTM Stand. G99, 1 (2010).

11. J. W. Eaton, D. Bateman, S. Hauberg, and R. Wehbring, (2016).

12. D. Tabor, The Hardness of Metals, First (Oxford University Press, Oxford, 1951).

13. K.-H. Zum Gahr, Microstructure and Wear of Materials (1987). 